\title{
A SEMANTIC ANALYSIS OF PHRASAL VERBS PRODUCED BY HILLARY CLINTON IN THE COMMENCEMENT SPEECH
}

\author{
Asriyani Medina ${ }^{1}$, Ria Saraswati ${ }^{2}$ \\ ${ }^{1.2}$ Universitas Indraprasta PGRI \\ Jl. Nangka Raya No.58 C Tanjung Barat, Jakarta Selatan 12530, Indonesia \\ Corresponding Author(S): medinaasriyani@gmail.com
}

\begin{abstract}
:
The aim of this research is to analyse a semantic analysis of phrasal verbs produced by Hillary Clinton in her commencement speech. The writer focused on the implied meanings and the phrasal verbs produced by Hillary Clinton in her speech at Wellesley College in 2017. In this analysis, the writer used a qualitative descriptive method and a library research technique to collect the data. In analysing the implied meanings of phrasal verbs, the writer applied Geoffrey Leech's theory. According to the result, the writer found that there were 10 or $25 \%$ phrasal verbs with conceptual meaning, 4 or $10 \%$ phrasal verbs with connotative meaning, 16 or $39 \%$ phrasal verbs with affective meaning, 7 or $17 \%$ phrasal verbs with social meaning, and 3 or $9 \%$ with thematic meaning. Therefore, the most dominant meaning in phrasal verbs used by Hillary Clinton was affective meaning. Meanwhile, in analysing the phrasal verbs, the writer used the theory from Larsen-Freeman and CelceMurcia. There were three types of phrasal verbs categorized into literal phrasal verbs, aspectual phrasal verbs, and idiomatic phrasal verbs. It can be concluded that there were 17 or $42 \%$ literal phrasal verbs, 10 or $25 \%$ aspectual phrasal verbs, and 13 or $33 \%$ idiomatic phrasal verbs. Thus, the most frequent type of phrasal verbs used during the speech was literal phrasal verb.
\end{abstract}

Keywords:

semantic analysis, implied meanings, phrasal verbs, Hillary Clinton

\section{INTRODUCTION}

Language is a system of communication which is largely employed by humans to persuade, convince, criticize, inform and influence from one to another either by written or spoken language. It is said that humans have disparate methods to utter their intention or to convey their feelings through a language; therefore, the way humans communicate to deliver information and aim lead to the distinction of the way animals do. It can be said that language has become the basic and essential need for humans to live together as the relation between humans is connected by language. The use of language is an integral part of being human (Aitchison, 2003). As a result, to produce similar meanings and perceptions, every language has been systematically set out to form its fixed-combination and rules in order to construct a simple structure, thus both speaker and the addressee can fully comprehend it. 
The study of language has been closely examined scientifically to discover how a language can be structured from its smallest unit. Regarding the use of it and the production of it to be well-organized and clearly understood, linguistics plays an immense role and has been assumed as the core of language. According to Varga (2010:21) "Linguistics is the scientific study of language. The product of linguistics is an objective, systematic, and explicit account of (some aspect of) language." Without determining its correctness, linguistics centralizes its concern by describing language in all aspects with the perception as descriptive, not prescriptive since it accentuates the spoken language primarily rather than written language. In other words, linguistics, in particular, perceives what is said instead of what ought to be said as it follows a natural language processed by humans; and the target is on expressing what humans feel rather than what humans plan to feel.

The scope of linguistics covers many essential disciplines in producing language, and one of them is semantic as the study of meaning. To enable humans communicating effectively, it is evident that meaning has a particular part to be learned, embarking on the precise meaning of the words and the sentences produced in both formal and informal languages. Griffiths (2006:1) describes semantics as the study of the "toolkit" for meaning; knowledge encoded in the vocabulary of the language and in its patterns for building more elaborate meanings up to the level of sentence meaning. Without its presence, it is infeasible to understand the meanings of messages uttered by an author or a speaker due to the fact that the implied meaning of a word, a sentence or an expression can be variously interpreted. In general, semantics assists humans in distinguishing and classifying what appropriate words or expressions should be spoken and written in certain situations. Furthermore, meaning as an integral part of language holds a vital role in determining the purpose of a message such as persuading, convincing, informing, or expressing particular emotions.

When humans express their feelings, or give opinion and thought, sometimes, there are specific purposes or intention implied behind the language used, and they are often implicit. It means that not all words and utterance reflect what interpreted exactly in the dictionaries. They may not convey literal meanings rather represent humans' actual feelings through language; for instance, critics addressed to most public figures or politicians in newspapers or other forms of online news are sometimes written in sarcastic comments. This could also happen when in speech a speaker uses a sarcastic remark. This might create multiple perspectives for the readers or listeners toward what meanings are implied. Therefore, due to the variations of meaning created by humans, meaning itself is divided into different parts in order to get more detailed explanation of what literal or vague expressions made. Moreover, to be able to identify the implied meanings, humans definitely need to learn more deeply the study of meaning.

Leech asserts (1985:9) that distinguishing types of meaning can be done carefully to fit them into the total composite effect of linguistic communication. Leech (1985:10) has broken down the basic types of meaning into seven namely conceptual, connotative, social, affective, reflected, collocative and thematic. Each of them has its own specification to define meanings according to speakers' or writers' intention. 
Table 1 Seven Basic Types of Meaning (Geoffrey Leech, 1985)

\begin{tabular}{|c|c|}
\hline TYPE OF MEANING & DESCRIPTION \\
\hline Conceptual meaning & $\begin{array}{l}\text { Conceptual gives a logical meaning in which the word can be } \\
\text { interpreted comprehensibly without any implied meaning. }\end{array}$ \\
\hline Connotative meaning & $\begin{array}{l}\text { Connotative represents what a word refers to and gives } \\
\text { reference for what people believe about the word and its } \\
\text { meaning in the society. }\end{array}$ \\
\hline Social meaning & $\begin{array}{l}\text { Social meaning connects the purpose of utterance which can be } \\
\text { interpreted as requesting, asserting, apologizing, and etc }\end{array}$ \\
\hline Affected meaning & $\begin{array}{l}\text { Affected meaning reflects speaker's true feelings that could } \\
\text { affect the listeners. }\end{array}$ \\
\hline Reflected meaning & $\begin{array}{l}\text { Reflected meaning has multiple meanings where one sense } \\
\text { influences our response to another sense. }\end{array}$ \\
\hline Collocative meaning & $\begin{array}{l}\text { Collocative means that the meaning sets the word to have its } \\
\text { pair such as pretty and handsome that share common ground in } \\
\text { the meaning 'good-looking' }\end{array}$ \\
\hline Thematic meaning & $\begin{array}{l}\text { Thematic is where the message is organized in term of order or } \\
\text { emphasis (the use of passive and active voice can influence the } \\
\text { aim and the focus of the speaker or writer). }\end{array}$ \\
\hline
\end{tabular}

By specifying the meaning into more comprehensive elaboration, this would ease the readers or listeners to understand what aim a speaker or writer intends to present, and how the selective utterance could represent a writer or a speaker's true feeling.

Defining the implied meaning in an utterance should begin with a smaller part of language which is a word. The use of English lexical resources depends on the habitual expressions made by the speakers. In term of spoken language, native speakers generally use their daily expression, while English learners tend to encounter difficulties to be familiar with it. One of the examples is the use of phrasal verbs. Phrasal verbs are widely learned by most English learners to make their speaking skill seemed more natural as the native speakers do. It is stated by McCarthy (2004:4) that phrasal verbs are verbs that consist of a verb and a particle (prepositions or adverbs), and a phrasal verb can have different meanings. McCarthy (2004:14) also emphasizes that sometimes there is no direct connection between the various meanings, therefore, the best method to memorize phrasal verbs is by learning each different meaning of them and applying them into sentences. In other words, there is no way for English learners making phrasal verbs are memorized well except getting used to applying them in daily language.

Larsen-Freeman and Celce-Murcia (2015:448) clearly distinguish types of phrasal verbs into three according to their semantic features which are literal phrasal verbs, aspectual phrasal verbs, and idiomatic phrasal verbs.

Table 2 Types of Phrasal Verbs (Larsen-Freeman \& Celce-Murcia (2015) TYPE OF PHRASAL DESCRIPTION VERBS

\begin{tabular}{cl}
\hline Literal Phrasal Verbs & $\begin{array}{l}\text { Literal means original; and literal phrasal verbs mean that the phrasal verbs can } \\
\text { be clearly understood as the particle retains its prepositional meaning, and the } \\
\text { combination is fully compositional. Literal phrasal verbs including sit down, } \\
\text { stand up, take down, climb up, and fall down should not be difficult for learners } \\
\text { to comprehend and produce. }\end{array}$ \\
\hline Aspectual Phrasal Verbs & $\begin{array}{l}\text { Aspectual phrasal verbs have the combination that represents the meaning as not } \\
\text { transparent, but not completely idiomatic either. This type sees particle } \\
\text { contribution and divides the phrasal verbs into sub-classes based on semantic } \\
\text { features namely inceptive which gives signal of a beginning state (i.e., set up, start } \\
\text { up), continuative that shows continuing action (in this sub-class the use of } \\
\text { particles are divided into four and one of them are along and on such as in keep } \\
\text { on, come along, and etc.), iterative that shows repetition (i.e. write over, think }\end{array}$ \\
\hline
\end{tabular}




\begin{tabular}{cl}
\hline & $\begin{array}{l}\text { over and etc), and lastly completive that shows the activity is complete (i.e. burn } \\
\text { down, clean up, check over and etc.). }\end{array}$ \\
\hline Idiomatic Phrasal Verbs & $\begin{array}{l}\text { Idiomatic phrasal verbs that are quite difficult to define since the particles do not } \\
\text { contribute to the meaning of verbs, but rather give different meaning along with } \\
\text { its fixed-combination of a verb and a particle, such as bring about, walk into, and } \\
\text { etc. }\end{array}$
\end{tabular}

According to Downing and Locke (2006:336), "No student of English can fail to notice that phrasal verbs are one of the most distinctive features of present-day informal English, both in their abundance and in their productivity." It is clear from the statement that phrasal verbs use refers to spoken language. Although some phrasal verbs can be applied in written language, however, they seem to be appeared more in spoken language.

Without any exception, formal speech is included as a spoken language; thus, phrasal verbs could be applied here as well. Formal speech is given in any special occasions, and one of them is commencement speech. Commencement speech is a formal talk by a speaker or a guest speaker to commemorate university or college graduates in a graduation day. Public figures and politicians are frequently invited as the guest speaker. Since this occasion is mostly attended by native speakers as the audiences, it will be more flexible for the speaker to use phrasal verbs during the speech. Hillary Clinton has become one of politicians who has been regularly invited to give her commencement speech. The way she tailored the words to persuade, convince and even criticize the government was excellently executed as well as she applied some phrasal verbs during her speech especially at Wellesley College graduation day in 2017. This research focused on a semantic analysis of phrasal verbs produced by Hillary Clinton, and the aim was to answer the questions: What are the implied meanings of phrasal verbs produced by Hillary Clinton in the commencement speech and what types of phrasal verbs produced by Hillary Clinton in the commencement speech.

\section{METHOD}

The method used to conduct the research becomes the most integral part since it is the scientific means to gather the data with specific purposes and usefulness. In analyzing the semantic use of phrasal verbs by Hillary Clinton in her commencement speech, the writer used qualitative descriptive method. Qualitative refers to the research procedure which results from written words or spoken language to present descriptive data. Data and facts comprising phrasal verbs or text reinforce this qualitative research came from the speech of Hillary Clinton at Wellesley college in 2017. To do this research, the writer looked for the references from the prior research, and other sources from the internet.

To find out the implied meanings of phrasal verbs, the writer used Geoffrey Leech's theory by selecting 5 of basic meaning types which are literal, connotative, affective, social, and thematic. Meanwhile, to figure out what phrasal verbs types produced by Hillary Clinton, the writer used Celce-Murcia and Larsen-Freeman's theory consisting of literal phrasal verbs, aspectual phrasal verbs, and idiomatic phrasal verbs. There were 40 phrasal verbs taken from the speech and divided into two different parts of analysis which were the implied meanings the phrasal verbs and types of phrasal verbs.

It is necessary to verify how valid the data is. By doing so, we can guarantee the credibility of data. In this research, the writer employed triangulation as the technique of data validity test. Triangulation is the technique to check the reliability taken from several sources by applying various ways. The writer applied multiple data sources as one of triangulation techniques. 


\section{RESULTS AND DISCUSSION}

According to the research finding, the writer found different implied meanings and phrasal verbs types in this commencement speech. Regarding the implied meaning, most phrasal verbs are from affective meaning that reflect the true feeling from the speaker and give impact to the listeners, as in this speech Hillary Clinton mostly criticized the government and showed her disappointment and displeasure of the presidential election in 2017. Therefore, affective is the most dominant, accounting for 16 or $39 \%$. Conceptual meaning holds 10 or $25 \%$, while social meaning has a slight number than the latter, comprising 7 or $17 \%$. Connotative and thematic meanings have almost similar numbers, which are 4 or $10 \%$ and 3 or $9 \%$ respectively.

According to the result from the types of phrasal verbs related to the semantic context, most of the phrasal verbs used by Hillary Clinton are literal phrasal verbs which are 17 or $42,5 \%$. The rest has almost similar numbers, in which 13 or $32,5 \%$ for idiomatic phrasal verbs, and 10 or $25 \%$ for aspectual phrasal verbs. It is clear that although Hillary Clinton is a politician who always attends formal conferences, during her spoken language, she still uses phrasal verbs to express and state her feelings. Most literal phrasal verbs can be understood clearly and logically. This means she knows how to show her clarity in delivering her speech, though there are many idioms too.

\section{Affective Meaning}

Affective meaning shows the true feeling of the speaker such as displeasure, friendliness, or sarcastic expressions. Most of the messages in Hillary Clinton's speech was about her disappointment, anger and dissatisfied over the 2016 presidential election, which she was one of the candidates; and the condition and issues spread in the USA at that time. Therefore, affective meaning mostly found in her speech. There are 16 phrasal verbs with this type of basic skill.

For example, "To thank her, the trustees, families, friends and faculty staff and guests for understanding and perpetuating the importance of this college, what it stands for and what it has meant and what it will do in years ahead."

This part was uttered as her opening speech. Hillary Clinton here was showing her gratitude to be invited as a guest speaker. She also showed her pride by seeing the graduates sitting in front of her as audiences, celebrating their graduation day. This phrasal verb implies affective meaning since there is an implicit meaning of stand for which is showing the true feeling of the speaker. The use of 'it' refers to this college. She felt proud of the college for what it has contributed to the students and practitioners. She used a casual tone to express her friendliness.

Another example can be described taken from this part " "Make defending truth and a free society a core value of your life every single day. So, wherever you wind up next the minute you get there, register to vote."

According to Oxford Learner's Dictionary, wind up means to find yourself in a particular place or situation. In this speech, wind up implies affective meaning as Hillary Clinton showed her sarcastic tone. As can be seen above, in this part when Hillary Clinton mentioned 'you', it refers to the people as a whole. "When she said wherever you wind up next the minute you get there, register to vote" she raised her tone and emphasized the statement to remind the audiences to vote and use their voices during the elections as they 
have their rights to do that. She referred to free society as the main part in her country and therefore, she tried to persuade the audiences to participate the election. The reason why this becomes affective is because it reflects her personal feeling and the message would later give impact to the audiences.

Table 3 Phrasal Verbs with Affective Meaning

\section{UTTERANCE}

"To thank her, the trustees, families, friends and faculty staff and guests for understanding and perpetuating the importance of this college, what it stands for and what it has meant and what it will do in years ahead"

"And by the way, we were furious about the past presidential election of a man whose presidency would eventually end in disgrace with his impeachment for obstruction of justice."

"Make defending truth and a free society a core value of your life every single day. So, wherever you wind up next the minute you get there, register to vote."

\section{PHRASAL VERBS}

stand for

end in

wind up

\section{Conceptual Meaning}

Conceptual means that the implied meaning in a word gives basic meaning/concept, and it is logical to be translated. In this category, there are 10 phrasal verbs with conceptual meaning found from the speech.

For instance, "As President Johnson said I spoke at my commencement 48 years ago; I came back 25 years ago to speak at another commencement." I couldn't think of any place I'd rather be this year that right here."

According to Oxford Learner's Dictionary, come back means to return. I came back here means when President Johnson returning to the college as a guest speaker back then 48 years ago. Hillary Clinton only retold and informed the audiences what President Johnson said in his commencement speech. It is clear that the implied meaning of come back here is conceptual and reflects the basic meaning since there is no particular feeling, only retelling.

The second phrasal verb can be observed taken from the utterance when she said "I do remember my commencement. I'd been asked by my classmates to speak. I stayed up all night with my friends, the third floor of Davis."

According to Oxford Learner's Dictionary and Cambridge Online Dictionary, stay up means going to bed later than usual. In this part, Hillary Clinton was only telling her experience when she was a student at Wellesley College where she was asked to be a speaker in her commencement speech, and stayed up all night to prepare the things for her speech. Therefore, in this context, stay up is comprehensible since it matches the dictionary meaning, and gives basic meaning of phrasal verb without expressing any particular feeling.

Table 4 Phrasal Verbs with Conceptual Meaning

\section{UTTERANCE}

"As President Johnson said "I spoke at my commencement 48 years ago; I came back 25 years ago to speak at another commencement. I couldn't think of any place I'd rather be this year that right here."

"I do remember my commencement. I'd been asked by my classmates to speak. I stayed up all night with my friends, the third floor of Davis."

\section{PHRASAL VERBS}

came back

stayed up 
"You've spoken out against racism and sexism and xenophobia and spoken out discrimination of all kinds."

\section{Social Meaning}

Social meaning means that the social status of a person can affect the utterance to be understood. Style, status, and illocutionary also play major parts in this meaning. There are 7 phrasal verbs found with social meaning.

It is seen from this part when Hillary Clinton said "You are graduating at a time when there is a full-fledged assault on truth and reason. Just log on to social media for 10 seconds it will hit you right in your face."

According to Oxford Learner's Dictionary, $\log$ on means to perform the actions that allow you to begin using a computer system, application or online account. It can also refer to allowing somebody to begin using a computer system, application or online account. This use relates to computers topic. The CEFR level shows that this phrasal verb includes in B1 or equals intermediate or independent user/speaker.

Regarding the illocutionary force, the use of $\log$ on represents an assertion or a command. The following phrase "it will hit you right in your face" also shows warning. It seems Hillary Clinton warned the audience how social media could provide unreliable truth and reason. From the category of social meaning, it is clear that the status of this phrasal verb is still casual and colloquial as this is familiar for people using computers or any websites in this era.

Moreover, social implied meaning is also spotted when she said "I can still remember the professors who challenged me to make decisions with good information, rigorous reasoning, real deliberation. I know we didn't have much of that in this past election, but we have to get back to it."

Get back is one of the most common phrasal verbs used in informal language. There is only one meaning of get back according to Oxford Learner's Dictionary means to return to something. Meanwhile, regarding the CEFR this phrasal verb includes in A2 level or equals elementary or basic user/speaker.

In this part, she was sharing her experience at Wellesley college where her professor used to encourage her to be a more critical person and challenge her to give factual decision supported by the evidence and reasoning, while in the past election the USA lacked on this, according to her. The use of get back refers to return to the moment where good decisions should be made up by looking at rigorous reasoning and real deliberation as it used to be whereas the past election did not apply this. The meaning of get back implies social meaning as regarding the illocutionary force, the statement "we have to get back to" shows assertion and persuasion. The use of modality have to supports this reason too.

Table 5 Phrasal Verbs with Social Meaning UTTERANCE PHRASAL VERBS

"You are graduating at a time when there is a full-fledged assault on truth and reason. Just log on to social media for 10 seconds it will hit you right $\log$ on in your face."

"Look at the budget that was proposed in Washington, it is an attack of unimaginable cruelty. I'm the most vulnerable among us, the youngest, the 
oldest, the poorest, and hard-working people who need a little help to gain

or hang on to a decent middle-class life."

"I can still remember the professors who challenged me to make decisions with good information, rigorous reasoning, real deliberation. I know we didn't have much of that in this past election, but we have to get back to

get back it."

\section{Connotative Meaning}

Connotative meaning gives reference for what people believe about the word and its meaning in society. In other words, its meaning interprets what the word refers to. In this category, there are only 4 phrasal verbs that have connotation meanings.

This can be observed when she uttered "I told the trustees I was sitting with, after hearing tallest speech, I didn't think I could get through it. So, we'll blame allergy instead of emotion."

According to Oxford Learner's Dictionary, get through has several meanings; to use up a large amount of something, to manage to do or complete something, to be officially accepted, and to make somebody to be successful in exam. Get through in this context has the meaning of managing something to do or completing something. Get through has the connotation of having some difficulties in some situations but finally people manage to achieve it. The meaning refers to something hard to be obtained or accomplished and seems impossible. It is clear that the aim of Hillary Clinton saying this was to state her assumption of not being able to complete the speech successfully.

Another one taken from this part "Drumming up rampant fear about undocumented immigrants, Muslims, minorities, the poor, turning neighbour against neighbour and sowing division at a time when we desperately need unity."

According to Oxford Learner's Dictionary, drum up means trying hard to get support or business. In this part, the use of drum up has negative connotation meaning. It is clear that Hillary Clinton criticized the media that has blown up rumours massively. She expressed her resistance of the rumours mostly being talked about in her country. In this context, drum up means having much effort to get acceptance and support of the issues in the country such as undocumented immigrants, Muslims, minorities or discord between neighbourhoods. Drum up in this part implies implicit meaning which is spreading fear in their country.

Table 6 Phrasal Verbs with Connotative Meaning

\section{UTTERANCE}

"I told the trustees I was sitting with, after hearing tallest speech,

I didn't think I could get through it. So, we'll blame allergy instead of emotion."

"Drumming up rampant fear about undocumented immigrants, Muslims, minorities, the poor, turning neighbour against neighbour and sowing division at a time when we desperately need unity."

"Vaslav Havel the dissident playwright, the first president of

Czech Republic wrote an essay called the power of the

powerless, and in it he said the moment someone breaks through

in one place when one person cries out, the emperor is naked."

\section{PHRASAL VERBS}

get through

drum up

cries out 


\section{Thematic Meaning}

Thematic meaning deals with structure choice in sentences. Passive and active forms can determine the aim of the speaker or writer. There are only 3 phrasal verbs found with thematic meaning from the speech.

For instance, "I've got to spend time with my family especially my grandchildren. I was going to give the entire commencement speech about them, but was talked out of it."

From the part above, the clause but was talked out of it, the subject here refers to Hillary Clinton herself. It means she was told and not allowed to give the commencement speech about her grandchildren. The focus of this phrasal verb is clear; Hillary Clinton herself as the agent where the active voice could be My family told me not to talk about my grandchildren. This implies thematic meaning as the focus of the expression relies on the use of the sentence form, which is passive voice in this part.

Another one comes from the phrasal verb left out. "A lot of our fellow Americans have lost faith in the existing economic, social, political and cultural conditions of our country. Many feel left behind, left out."

According to Oxford Learner's Dictionary, leave out means to not include or mention somebody/something in something. Many here refers to Americans, and left out in this context means many Americans felt not being included or part of the country since they have lost their faith. It is clear that the use of passive form here is because the focus of the sentence is not who made the Americans lost their faith and left out, but the focus is in the Americans themselves who were affected by the issue, therefore, this implies thematic meaning.

Table 7 Phrasal Verbs with Thematic Meaning

\begin{tabular}{lc}
\hline \multicolumn{1}{c}{ UTTERANCE } & PHRASAL VERBS \\
\hline "I've got to spend time with my family especially & talked out of \\
my grandchildren. I was going to give the entire \\
commencement speech about them, but was talked \\
out of it." \\
\hline "A lot of our fellow Americans have lost faith in the \\
existing economic, social, political and cultural \\
conditions of our country. Many feel left behind, left \\
out."." \\
\hline "Millions of people will be hurt by the policies \\
including this budget that is being considered. And \\
many of those same people don't want dreamers \\
deported or healthcare taken away."
\end{tabular}

\section{Types of Phrasal Verbs}

Regarding the types of phrasal verbs observed from the speech, there are literal, aspectual, and idiomatic. The types of phrasal verbs mostly used by Hillary Clinton are literal phrasal verbs which are 17, while the rest has almost similar numbers, 13 for idiomatic phrasal verbs, and 10 for aspectual phrasal verbs. 


\section{Literal Phrasal Verbs}

Literal means original. Phrasal verbs with literal meaning are logically understood and not difficult to be comprehended by the learners. There are 17 literal phrasal verbs found in the speech.

The first phrasal verb can be observed is wait for. According to Cambridge Online Dictionary, wait for means if something waiting for you, it has been left or prepared for you to collect, use, enjoy, or deal with when you arrive. The particle for here does not change the meaning of wait, so it is easily understood, and it has equal meaning without the particle for if we only use the word wait as singular verb, therefore, the meaning is literal.

Another one is the use of come back. Come back means returning. It is clear if the word come with the particle back is interpreted, it means return or go back. The particle back here affects the meaning of come but still logically comprehended, especially for English learners. The combination of come and particle back is fully compositional; therefore, come back has literal meaning.

\section{Aspectual Phrasal Verbs}

Aspectual phrasal verbs have the combination which are not transparent, but it is not completely idiomatic either. There are categories divided in this aspectual namely inceptive, continuative, iterative and completive. The writer found 10 aspectual phrasal verbs in the speech.

Firstly, the use of get through can be categorized into continuative aspect. Continuative by using preposition through refers to something from beginning to end. According to Oxford Learner's Dictionary, get through means managing to do or complete something, and this matches the category of continuative. It can be said as aspectual, since the word get and through can still be clearly understood but not really transparent to be interpreted directly.

The next can be analysed is the use of rev up. Rev up is categorized into inceptive subclass where the particle in this sub-class gives signal of a beginning state. According to Cambridge Online Dictionary, rev up means to become more active, or to make someone or something become more active. The particle up affects the word rev although the meaning of the word rev has almost similar meaning with this phrasal verb. According to Cambridge Online Dictionary, rev as a single word means to increase the speed of the engine of a vehicle while the vehicle is not moving. It is clear the context particle $u p$ here is to emphasize the word rev, and it is aspectual since the combination is still understood and it includes in continuative sub-class.

\section{Idiomatic Phrasal Verbs}

Idiomatic phrasal verbs have various and not obvious meanings. The particles cannot be interpreted singularly as well as the verb. There are 13 idiomatic phrasal verbs in the speech.

The first example is clearly seen from the use of stick it out. Stick (something) out has different meaning with the word stick without the particle. According to Oxford Learner's 
Dictionary, stick means to fix something to something else, usually with a sticky substance; to become fixed to something in this way, while stick (something) out means to continue doing something to the end, even when it is difficult or boring. This combination cannot be interpreted singularly, and the verb stick without the particle is also different in context. This phrasal verb has a fixed- meaning and not obvious to be understood since the meaning does not reflect the original meaning of the verb; therefore, this phrasal verb is idiomatic.

The last one can be analysed from wind up. Wind up is categorized into idiomatic since the word wind and the particle up do not have any relation to create a literal meaning. According to Oxford Learner's Dictionary, wind up means to find yourself in a particular place or situation, while the word wind without the particle up refers to turning or causing something to turn. The particle up does not modify the meaning of the verb wind, and the context is different too. It creates different meaning when the combination is formed as the phrasal verb wind up.

Table 8 Types of Phrasal Verbs

\begin{tabular}{lcc}
\hline \multicolumn{1}{c}{ UTTERANCE } & PHRASAL VERBS & TYPES OF PHRASAL \\
VERBS
\end{tabular}

\section{CONCLUSION}

According to the results, the writer can conclude that there were many phrasal verbs produced by Hillary Clinton in her commencement speech at Wellesley College in 2017. From the data found, the writer collected the implied meanings in phrasal verbs and then analysed the basic meanings based on Geoffrey Leech theory, where the writer only used 5 of them which are conceptual, connotative, affective, social, and thematic. From the research, there are 40 phrasal verbs with the percentage number of $100 \%$, consisting of 10 conceptual, 4 connotative, 16 affective, 7 social, and 3 thematic. It is clear that the most dominant implied meaning of phrasal verbs used by Hillary Clinton was affective 
since most of her aims were to express her true feeling, anger, displeasure, respect and friendliness where these points could give impact to the audiences. On the other hand, the writer also examined closely the types of phrasal verbs produced by Hillary Clinton in her commencement speech. The writer used the theory from Larsen-Freeman and CelceMurcia who categorized phrasal verbs into three different categories which are literal phrasal verb, aspectual phrasal verb, and idiomatic phrasal verb. The numbers of data analyzed are similar with the implied meanings which are 40 phrasal verbs with the percentage number of $100 \%$, comprising 17 literal phrasal verbs, 10 aspectual phrasal verbs, and 13 idiomatic phrasal verbs. As can be seen that literal phrasal verbs have the most significant number since the phrasal verbs used were easily comprehended, and common in daily conversation.

\section{REFERENCE}

Cruse, A. (2000). Meaning in language: An introduction to semantics \& pragmatics. New York: Oxford University Press

Downing, A., \& Locke. (2006). English grammar a university course. London \& New York: Taylor \& Francis Group.

Ghailan, G. G. (2015). A semantic study of phrasal verbs in mark twain's selected short stories. (A Thesis of Master Degree, University of Baghdad,2015) Accessed from https://www.researchgate.net/publication/330358371_A_Semantic_Study_of_Phr asal_Verbs_in_Mark_Twain's_Selected_Short_Stories

Hart, C. W. (2017). The ultimate phrasal verbs book ( $3^{\text {rd }}$ ed). New York: Simon and Schuster.

Larsen-Freeman, D., \& Celce-Murcia, M. (2015). The grammar book: Form, meaning and use for English language teachers . Boston, MA: National Geographic Learning.

Monika, M. M. (2020). An analysis of phrasal verb errors used by fifth semester students of english study program of IAIN Bengkulu (A Descriptive Qualitative Study on Students Phrasal Verb Errors at Fifth Semester Students of English Study Program of IAIN Bengkulu in Academic Year 2018/2019). (A Thesis for Bachelor Degree Fulfillment,2020) Accessed from http://repository.iainbengkulu.ac.id/4475/1/ DINI\%20MONA\%20MONIKA\%201526230027\%20An\%20Analysis\%20of\%20 Phrasal\%20Verb\%20Errors\%20Made\%20by\%20Fifth\%20Semester\%20Students $\% 20$ of\%20English\%20.pdf

Pardede, H. (2016). Semantics: A view to logic of language. Pematang Siantar: FKIP Nommensen

Saeed, J. I. (2009). Semantics ( $3^{\text {rd }}$ ed). Singapore: Utopia Press Pte Ltd

Thyab, R. A. (2019). Phrasal verbs in english as a second/foreign language. Arab World English Journal, 10.

Varga, L. (2010). Introduction to linguistic: A companion to the seminar. Budapest: Eotvos: Lorand University.

Zdrakovic, N. (2018). The meaning of meaning: Leech's seven types of meaning in comparison to palmer's and lyons' approaches. European Master in Lexicology. 510. May 10, 2021. https://www.researchgate.net/publication/335272788_ The_Meaning_of_Meaning_Leech's_Seven_Types_of_Meaning_in_Comparison_ to_Palmer's_and_Lyons'_Approache 